\title{
NOTES ON RAYON STAPLE FIBRE
}

W E ARE, no doubt, all aware of the tremendous strides which have been made in the production of filament rayon, but, in all probability, few of us realize the extent of the progress made by filament rayon's direct descendant, staple fibre. As wood is the raw material used in the manufacture of this comparatively new product, which is bound to bulk large in the textile industry of the future, foresters should know more about it.

\section{Rate of Growth of Staple Fibre}

Based on proven statistics, R.S.F. seems bound to far outdo its parent, filament rayon. No other man-made fibre has produced the far reaching effects in textile manufacturing, merchandising and styling that the spun rayon product has. As an indication of the rate of growth of R.S.F. it may be stated that in 1928 United States textile spinning mills consumed only $165,000 \mathrm{lbs}$. of domestic manufacture, and imported 200,000 lbs., while in the year 1939 the consumption amounted to over 100,000,000 lbs., approximately one-half of which was of domestic production and the other half imported. This is truly an amazing growth.

\section{What is Staple Fibre?}

The first question the layman asks is, "What is staple fibre?"

Rayon staple fibre consists of rayon filaments which have been cut to known, uniform lengths by the producer of rayon, made by the same process as the filament yarn.

R.S.F. may be spun into yarn on a cotton, schappe, or a woollen or worsted spinning system, after which it is called spun rayon yarn.

It is important to note that rayon staple fibre should be sharply distinguished from rayon waste. The latter is simply a by-product of rayon filament yarn, or the waste from staple fibre manufacture itself. These waste products, in each case, lack uniformity of quality, whereas R.S.F. is a primary product of uniform quality.

\section{Why Use Staple Fibre}

There are many reasons for the rapidly increasing use of staple fibre, and one of the most important is its great versatility. This feature is the more notable, of course, because of the variety of its raw material forms. Another point of importance is that R.S.F. is readily adaptable to the machinery designed and in use for the processing of other commonly used fibres. Probably its greatest asset, however, is that it makes possible the production of an almost limitless number of new, distinctive and unique self-blends, as well as a wide variety of blends with every other available fibre.

Progress in adaptations and use of staple fibre has been so rapid that it is almost impossible to keep an up-to-date recording. A true perspective is therefore lacking at the present time.

\section{Birth of Staple Fibre}

Germany produced the first rayon staple fibre during the first world war to supplement the limited supplies of cotton and wool available to her. 
It was not until the late 1920 's, however, that staple fibre started to come into its own, although in the preceding decade the production of rayon filament yarn had increased twelve-fold. In the last decade the R.S.F. industry has grown by leaps and bounds, so that to-day the world production is almost equal in volume to that of the filament product.

\section{Initial Stimuli by Governments}

To a large extent the amazingly rapid growth of R.S.F. has been due to the encouragement and protection given it by the governments of the "nationalistic" countries, namely Germany, Japan and Italy. In these countries the R.S.F. industry has been fostered as a part of their national economic policy because first, its use reduces their dependence on importation of cotton and wool; second, the importation from the countries which supply the raw material makes but slight demand upon their supply of foreign exchange, in comparison with cotton and wool; and third, they found in R.S.F. a product for which there was a ready export market. These three countries alone accounted for 90 per cent of the world production of rayon staple fibre in 1939.

\section{Stands on Its Own Feet To-day}

The present rapid increase in the production of R.S.F. in the United States and Great Britain has proven its ability to progress on its own merits,versatility, adaptability, style possibilities and consumer appeal.

In the United States the consumption of R.S.F. has far outstripped its production in that country. While the U.S. produced about 5 per cent of the total world production in 1939 it consumed 10 per cent.

The chief sources of U.S. imports of R.S.F. during 1939, in the order of their importance, were Great Britain, Italy, France, Japan and Germany. It may be significant to the reader that Canada does not produce a single pound of R.S.F.

\section{Raw Material, for R.S.F. Production}

By far the greater proportion of the R.S.F. produced uses, as its raw material, rayon manufactured by the viscose process, although increasing quantities of acetate rayon are being used.

The chemical processes for R.S.F. are the same as for the filament yarn, the only difference being in the spinning techniques and final processing of the fibres by the rayon producers. ${ }^{1}$

In the viscose process the cellulose base for staple fibre is the usual special chemical grade of wood pulp.

\section{Advantages to Spinner-Consumer}

A great advantage of R.S.F. from the viewpoint of the spinner-consumer, is that he receives a uniform product as his raw material, due to the fact that it has been possible for the producer to maintain definite control at all times. This feature also permits the spinner-consumer to order by specifica-

1 Whereas the spinneret which produces filament yarn as its final product has usually only from 20 to 100 holes, the spinneret used in the production of rayon for staple fibre has thousands of holes. 
tion. This represents a distinct advantage of R.S.F. over "natural" fibres, such as those of the cotton plant, sheep, and the silk-worm.

The spinner fully appreciates the possibilities of the wide variety of products which may be made from staple fibre as he is constantly on the lookout for the opportunity of producing new fabrics. Staple fibre has assuredly broadened his field to a remarkable extent.

\section{Consumer Goods}

Staple fibre has found its greatest use to date in the women's apparel field, e.g., in dresses, sports clothes, beach-wear, underwear, suits, skirts, blouses, scarves, etc., but is now making rapid strides in the men's-wear field, e.g., slacks, sportswear, beach-wear, business suits, hosiery, underwear and neckwear.

In the household R.S.F. has found its chief use to date in draperies, upholsteries and blankets. Evidence of its increasing use in the home is that three of the leading blanket manufacturers in the United States are widely distributing blankets of staple fibre, ranging from the service types to luxury cover-spreads. These firms are backing up their products with expensive nation-wide advertising campaigns, because they know that they have "the goods." They didn't put these blankets on the market until they had assured themselves of downright quality and value. The rug industry promises to have startling announcements to make in the near future with regard to staple fibre rugs. A little more testing and a few minor adjustments in manufactur. ing technique by some of the world's largest producers will be followed by the marketing of rugs of R.S.F. which may revolutionize the industry.

\section{The Future}

Because staple fibre fulfills the desired requirements of style, quality and price it has already progressed far in a remarkably short period of time, but even yet it would not seem to have got into its stride and it certainly has not yet developed its markets fully. Its great inherent advantages, plus the intensive research being applied to-day, cause even the best informed to hesitate in their predictions as to what great possibilities the future may have in store.

As every good manufacturer to-day insists on correlating his own problems with those of the man from whom he buys his raw materials on the one hand, and with those of the man to whom he sells his own products on the other hand, he is constantly on the alert for every new development.

Foresters also must attain this attitude of mind.

A. R. Fenwick. 